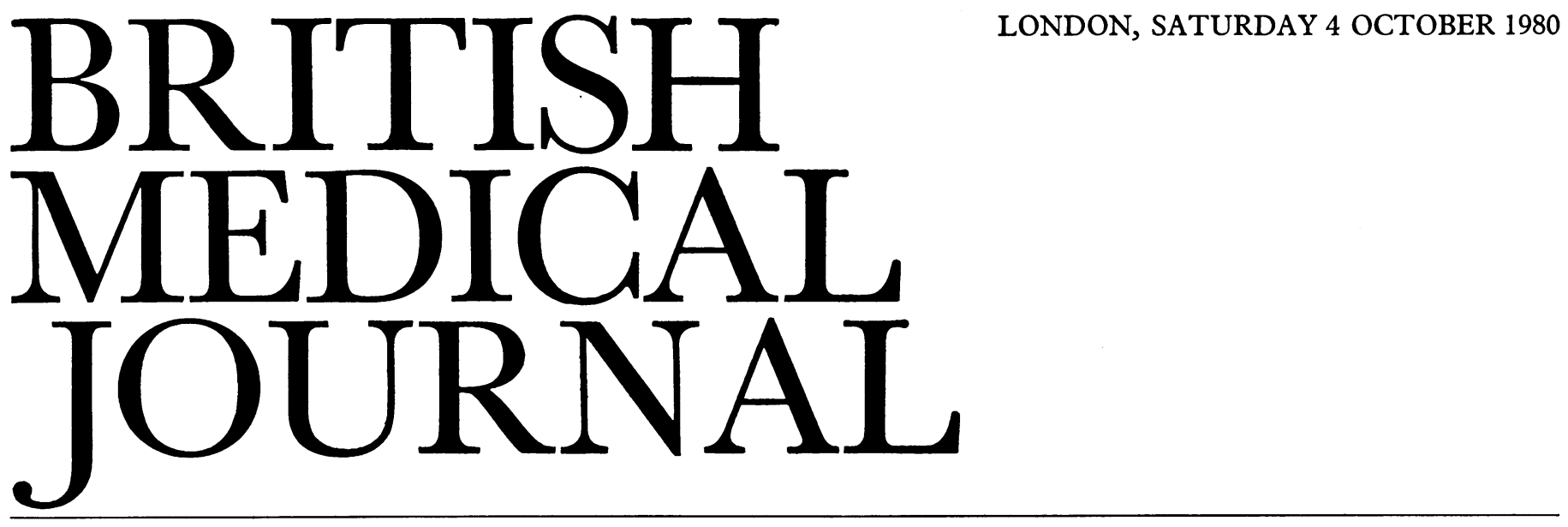

\title{
Endometriosis-continuing conundrum
}

For many years gynaecologists have suspected that the incidence of endometriosis is increasing, ${ }^{12}$ but facts on prevalence are still lacking. Many other epidemiological features of endometriosis are well defined: for example, it is commoner in the fourth decade of life, in the higher social classes, and in women who delay their first pregnancy. ${ }^{2}$ A recent genetic study $^{3}$ has shown that $7 \%$ of patients' first-degree relatives were also affected (compared with $1 \%$ of a control group), suggesting multifactorial inheritance.

The pathogenesis of endometriosis is another continuing topic of uncertainty. The theory that it results from metaplasia of peritoneal cells has received support from a recent histological study. ${ }^{4}$ Nevertheless, the more popular theory that it is caused by implantation of endometrial cells is supported by several observations: retrograde menstruation along the Fallopian tubes is frequently seen at laparoscopy; endometriosis may occur when the uterine cavity is opened ${ }^{5}$; and the condition can even occur after amniocentesis, ${ }^{6}$ repeated punctures at a single site being a possible contributory factor. Why endometrial cells should be able to become implanted in abnormal sites remains unknown.

The association between endometriosis and infertility has been the subject of recent speculation. Women with the disease have patent tubes ${ }^{7}$ and ovulation occurs almost normally, but the infertility may be due to the "luteinised unruptured follicle" syndrome-where the ovarian follicle fails to release the ovum despite going through all the other changes associated with ovulation. Such a syndrome would be undetectable by hormone assay, but a study based on laparoscopic examination of luteinised follicles showed that the stigmata of ovulation were absent in $79 \%$ of women with endometriosis compared with $6 \%$ of other infertile women. ${ }^{8}$ These results were not, however, confirmed in a later laparoscopic study ${ }^{9}$ of 199 infertile women, when stigmata were observed as frequently in the 83 patients with endometriosis as in the rest-and there was often doubt whether stigmata were present or not. The reason for the infertility associated with endometriosis remains uncertain. Perhaps a derangement of tubal function could produce retrograde menstruation as well as abnormal transport of the ovum-chronic salpingitis has been found in $33 \%$ of specimens from patients with endometriosis. ${ }^{7}$

In treating endometriosis, the choice-which lies between radical surgery, conservative surgery, and medical treatmenthas to be tailored to the needs of the individual patient. ${ }^{1}{ }^{10}$
Extirpation of the pelvic organs will cure severe disease in a woman whose family is complete, while at the other extreme a young asymptomatic patient may be treated by observation only, ${ }^{2}$ since the disease may regress, particularly if pregnancy occurs. The moderately or severely affected patient who wishes to have children requires medical treatment, conservative surgery, or a combination of both. Conservative surgery includes excision or diathermy of endometriotic areas, and in selected patients good results have been reported from laparoscopic electrocoagulation ${ }^{11}$ : complete relief of pain occurred in seven out of 11 patients, and pregnancy in six of the eight infertile patients.

Medical treatment aims at abolishing menstruation using oral contraceptives, progestogens, or danazol. The results of treatment with progestogens or oestrogen-progestogen mixtures are variable, ${ }^{2}{ }^{10}$ but there has been more optimism over the past 10 years since the introduction of danazol. Its mode of action is uncertain: the term "pseudomenopause" is inappropriate, since gonadotrophin concentrations remain normal (though peaks are absent and ovulation does not occur)..$^{12}$ Danazol binds to progesterone receptors ${ }^{14}$ and inhibits the production of ovarian ${ }^{15}$ and adrenal ${ }^{16}$ steroids probably at a point beyond where hormones act on the receptors. ${ }^{15}$ Some investigators ${ }^{13}$ have reported a decrease in plasma oestradiol concentrations during treatment, but others $^{12}$ have reported an increase. Clinical trials showed that danazol was superior to combined oestrogen-progestogen treatment in mild to moderate endometriosis, ${ }^{17}$ but it was ineffective $e^{17}$ or only partly effective ${ }^{18}$ in severe disease. Treatment has to be continued for six months; fortunately the side effects are mild, ${ }^{192}$ but unfortunately the drug is very expensive. Combined conservative surgery and treatment with danazol ${ }^{21}$ may achieve a remission rate of $90 \%$ and a pregnancy rate of $45 \%,{ }^{21} 22$ but the best way of combining the two remains uncertain. ${ }^{1017}$ The results of studies are difficult to compare because there is still no universally accepted classification for endometriosis.

${ }^{1}$ Scott RB, Te Linde RW. External endometriosis-the scourge of the private patient. Ann Surg 1950;131:697-720.

2 Venter PF. Endometriosis. S Afr Med f 1980;57:895-9.

${ }^{3}$ Simpson JL, Elias S, Malinak LR, Buttram VC. Heritable aspects of endometriosis: I. Genetic studies. Am f Obstet Gynecol 1980;137: $327-31$.

+ Czernobilsky B, Morris WJ. A histologic study of ovarian endometriosis with emphasis on hyperplastic and atypical changes. Obstet Gynecol $1979 ; 53: 318-23$. 
5 Szlachter NB, Moskowitz J, Bigelow B, Weiss G. Iatrogenic endometriosis: substantiation of the Sampson hypothesis. Obstet Gynecol 1980 55, suppl: 52-3.

6 Kaunitz A, Di Sant' Agnese PA. Needle tract endometriosis: an unusual complication of amniocentesis. Obstet Gynecol 1979;54:753-5.

${ }^{7}$ Czernobilsky B, Silverstein A. Salpingitis in ovarian endometriosis. Fertil Steril 1978 ;30:45-9.

${ }^{8}$ Brosens IA, Koninckx PR, Corveleyn PA. A study of plasma progesterone, oestradiol-17 $\beta$, prolactin and LH levels, and of the luteal phase appearance of the ovaries in patients with endometriosis and infertility. $\mathrm{Br} \mathcal{F}$ Obstet Gynaecol 1978;85:246-50.

9 Dmowski WP, Rao R, Scommegna A. The luteinized unruptured follicle syndrome and endometriosis. Fertil Steril 1980;33:30-4.

10 Hammond CB, Haney AF. Conservative treatment of endometriosis: 1978. Fertil Steril $1978 ; 30: 497-509$.

11 Hasson HM. Electrocoagulation of pelvic endometriotic lesions with laparoscopic control. Am f Obstet Gynecol 1979;135:115-21.

12 Hirschowitz JS, Soler NG, Wortsman J. Sex steroid levels during treatment of endometriosis. Obstet Gynecol 1979;54:448-50.

13 Chimbira TH, Anderson ABM, Cope E, Turnbull AC. Effect of danazol on serum gonadotrophins and steroid hormone concentrations in women with menorrhagia. Br f Obstet Gynaecol 1980;87:330-6.

14 Chamness GC, Asch RH, Pauerstein CJ. Danazol binding and translocation of steroid receptors. Am F Obstet Gynecol 1980;136:426-9.

15 Menon M, Azhar S, Menon KMJ. Evidence that danazol inhibits gonadotropin-induced ovarian steroidogenesis at a point distal to gonadotropin-receptor interaction and adenosine $3^{\prime}, 5^{\prime}$ cyclic monophosphate formation. Am F Obstet Gynecol 1980;136:524-30.

${ }^{16}$ Stillman RJ, Fencl MDeM, Schiff I, Barbieri RL, Tulchinsky D. Inhibition of adrenal steroidogenesis by danazol in vivo. Fertil Steril 1980; 33:401-6.

17 Noble AD, Letchworth AT. Medical treatment of endometriosis: a comparative trial. Postgrad Med F 1979;55, suppl 5:37-9.

18 Rönnberg L, Ylöstalo P, Järvinen PA. Effects of danazol in the treatment of severe endometriosis. Postgrad Med F 1979;55, suppl 5:21-6.

19 Fraser IS. Danazol-a steroid with a unique combination of actions. Scott Med F 1979;24:147-50.

20 Ward GD. Dosage aspects of danazol therapy in the treatment of endometriosis. Postgrad Med F 1979;55, suppl 5:7-9.

${ }^{21}$ Mettler L, Semm K. Clinical and biochemical experiences with danazol in the treatment of endometriosis in cases of female infertility. Postgrad Med f 1979;55, suppl $5: 27-32$.

${ }^{22}$ Audebert AJM, Larrue-Charlus S, Emperaire JC. Endometriosis and infertility: a review of sixty-two patients treated with danazol. Postgrad Med f 1979;55, suppl 5:10-3.

\section{Fish poisoning}

A variety of fishes and other marine creatures have toxic components that may produce illness. Shellfish are the most notorious-especially mussels, cockles, oysters, scallops, and queenies-and outbreaks of toxic food poisoning are not uncommon in Britain, especially in the summer. ${ }^{12}$ The toxin comes from the ingestion by the shellfish of certain species of planktonic dinoflagellates, which in warm summer conditions multiply rapidly, giving rise to so-called "red tides." These dinoflagellates produce a powerful curare-like neurotoxin in the digestive and respiratory organs of the shellfish. The toxin is harmless to the host but affects man, animals, and birds. It is water-soluble and heat-stable, and cooking does not appreciably destroy its poisonous properties-consumption of a fish bouillon has been known to produce temporary paralysis.

Clinically, the symptoms usually include a rash and some gastrointestinal upset; but more serious is the neurotoxic effect, which can cause loss of feeling in the hands, tingling in the mouth and tongue, weakness of the limbs, and difficulty in breathing. No direct antidote is known, so the treatment has to be symptomatic, together with general resuscitative measures if needed.

Recently, poisoning from vertebrate fishes has aroused considerable interest. On page 948 a report of ciguatera fish poisoning indicates the medical impact of new ethnic groups in the community. Apparently, any fish can become a source of this illness in man if it ingests material which is either toxic or the precursor of a toxin. Though more common in tropical waters, ciguatera poisoning could occur in some fish which are now sold in Britain, such as the red snapper.

The clinical features of ciguatoxin poisoning include an initial tingling of the lips, tongue, and throat; gastrointestinal symptoms, muscle weakness, and paralysis may follow. Death occurs in fewer than $10 \%$ of cases. Again the treatment is symptomatic. The message here is that if the traditional fish in our diet are to be replaced by new. species there will be a risk of unfamiliar types of fish poisoning.

Several fish in common use (members of the families Scombresocidae and Scombridae) tend to produce a scombrotoxin type of food poisoning. ${ }^{3}$ Fresh mackerel, tuna, and bonito are edible with no ill effects; but if these fish are allowed to spoil, owing to microbiological action in poor storage conditions, the histidine in the tissue changes to histamine. This (or possibly some other, unidentified toxin) produces an allergic reaction together with nausea and vomiting. Mackerel should always be cooked and eaten fresh, as spoilage can occur rapidly and cause scombrotoxic illness. Recently several incidents ${ }^{45}$ have been reported of people developing flushing, headache, urticarial rash, and vomiting and diarrhoea, starting 30 minutes to two hours after eating smoked mackerel. This is highly suggestive of the presence of scombroid toxin. Similar outbreaks have also been associated with canned mackerel, tuna, and bonito, and, in addition, with canned non-scombroid fish such as sardines and pilchards. The canned sardines most frequently responsible have been Moroccan, and the trade has voluntarily agreed to withdraw certain batches of $4 \frac{1}{2} \mathrm{oz}(130 \mathrm{~g})$ cans. This highlights the need for some checking of the storage and canning methods in the country of origin of imported canned foods. ${ }^{6}$

${ }^{1}$ Clarke RB. Biological causes and effects of paralytic shellfish poisoning. Lancet 1968;ii:770-1, 2.

${ }^{2}$ McCollum JPK, Pearson RCM, Ingham HR, Wood PC, Dewar HA. An epidemic of mussel poisoning in north-east England. Lancet 1968;ii: 767-70.

3 Anonymous. Fish poisoning. Lancet 1979;ii:1059-60.

${ }^{4}$ Communicable Disease Surveillance Centrc. Communicable Disease Repor $1979 ;$ Nos $17,40,41,42$.

5 Communicable Disease Surveillance Centre. Communicable Disease Report $1980 ;$ Nos 2, 27, 33.

Scottish Home and Health Department. The Aberdeen typhoid outbreak. Edinburgh: HMSO, 1964

\section{Prescription for social work}

For every publicly aired difference between doctors and social workers there are, no doubt, many instances of constructive co-operation. But the persistent disquiet in the medical profession-voiced at successive Annual Representative Meetings $^{12}$-about the effectiveness of social service departments suggests deficiencies in the contribution that social workers make to health care in the community. Nevertheless, doctors, with their scientific background, should be prepared to base any criticisms on hard evidence rather than publicitycatching anecdotes. Despite choosing a pejorative title, the authors of a recently published book, Can Social Work Survive,${ }^{3}$ make a convincing attempt to do this. Dr Colin Brewer, a psychiatrist, and June Lait, a sociology lecturer, have prepared a substantial body of evidence to support their catalogue of deficiencies in social work. Furthermore, they are 